\title{
Lung Function in Our Aging Population
}

\author{
W. Marek ${ }^{1}$ E. M. Marek ${ }^{1}$, K. Mückenhoff², H.-J. Smith ${ }^{3}$, N. Kotschy-Lang ${ }^{4}$, M. Kohlhäufl ${ }^{5}$ \\ ${ }^{1}$ Institute of Occupational Physiology, Augusta-Kranken-Anstalt, Bochum, \\ ${ }^{2}$ Institute of Physiology, Ruhr-Universität Bochum, \\ ${ }^{3}$ CareFusion, Höchberg, \\ ${ }^{4}$ Berufsgenossenschaftliche Klinik für Berufskrankheiten Falkenstein, \\ ${ }^{5}$ Klinik Schillerhöhe, Center for Pulmonolgy and Thoracic Surgery, Academic Teaching Hospital of the University of Tübingen, \\ Stuttgart-Gerlingen, Germany
}

\begin{abstract}
Aims of investigation: The chronological age of the Caucasian population and their anthropometrical data have significantly changed within the last five decades. Therefore the question arises whether or not the commonly used reference values of the European Community (ECCS) for lung function may still be accepted today. Since these values were obtained in the 1960s from subjects in a limited age range. For the elderly, the measured values are deduced by extrapolation beyond the range of reference equations which had been obtained in a different population. Therefore decisions concerning elderly and smaller subjects concerning remuneration due to impaired lung function after industrial exposure on the basis of EGKS values are questionable. Methods: Lung function tests were performed by pneumotachography, recording static lung volumes and flow-volume-curves in 262 asymptomatic non smoking males, aged 20 to 90 years. Measurements were performed with the MasterLab, or PneumoScreen systems (CareFusion, Höchberg). Results were compared to the reference values of ECCS, SAPALDIA and LuftiBus.

Results: For simplicity analysis of age and height dependence of investigated respiratory parameters (VC, FVC, $\left.\mathrm{FEV}_{1}, \mathrm{FEV}_{1} \% \mathrm{FVC}, \mathrm{PEF}, \mathrm{MEF}_{75,50,25}\right)$ can be described by linear functions $(\mathrm{y}=\mathrm{a} *$ height $-\mathrm{b} *$ age + c). The forced expiratory vital capacity, FVC, was calculated by $\mathrm{FVC}=0.0615^{*} \mathrm{H}-0.0308^{*} \mathrm{~A}-4.673 ; \mathrm{r}=$ 0.78. Mean FVC for younger subjects was found to be $104.7 \pm 10.7 \%$ of the ECCS reference values and 96.5 $\pm 11.8 \%$ in older subjects. For most parameters investigated linear regressions on age were steeper than described by the ECCS reference values. The regression of lung function to height largely follows the ECCS prescriptions.

Summary: Bochum lung function values of younger healthy subjects were higher compared to the reference values of the ECCS and showed a steeper age descent. The alternatively discussed reference values of the SAPALDIA-, or LuftiBus-Study are higher, but do not cover all necessary parameters and/or the age range. A multi centre study for contemporary reference values is recommended.
\end{abstract}

Key words: Lung function testing - reference values elderly males - spirometry - forced expiration

\section{INTRODUCTION}

In the last five decades, the chronological age distribution of our aging population has significantly changed along with anthropometrical data. In particular, body height increased, and life expectance increased significantly. Therefore the question arises whether or not the commonly used reference values of ventilatory lung function recommended by the European Community for Coal and Steel (ECCS) [1, 2], may still be accepted today, since these values were obtained in the sixties and seventies from subjects with a restricted range of age and body height. Birth cohort effects and improved technology should be considered. Measured values are classified for elderly by extrapolated reference equations, which have been obtained from a different population beyond the range. Therefore decisions in elder and smaller subjects concerning compensation due to impaired lung function after industrial exposure on the basis of ECCS-values are questionable. In the last decades several new reference equations were published, finding higher values for lung function [3-8], which replaced the former recommendations [9-13]. Compared to the recently published recommendations, ECCS-values are lower, and the lower limit values or the 5th percentile may not represent the cut off point between "normal" and "diseased". Current investigations try to describe lung function parameters from preschool children to senescence in one continuous formula taking into account a peak value in early adolescents [14].

Different models may be discussed for the changes in lung function related to aging. Firstly, after the age of 65 a normal time course of aging could result in a further linear decrease in spirometric parameters with the same slope as observed in middle aged groups [15], which would allow an extrapolation of the reference equations for the higher ages. Secondly, healthy older subjects may have nearly constant values or a plateau phase for lung function. Finally, accumulation 
of diseases may result in steeper deteriorations in lung function, as observed in patients with COPD or in heavy smokers [16-18].

Recently published reference formulas are incomplete concerning spirometric parameters (Hankinson [3], only FVC, FEV $1, F E V 6$, PEF, $\mathrm{FEF}_{25-75}$ ) the range of age (Brändli, [4] 20-60 years, $\mathrm{FEV}_{1}, \mathrm{FVC}$, $\mathrm{FEV}_{1} \% \mathrm{FVC}, \mathrm{PEF}, \mathrm{MEF}_{75,50,25}, \mathrm{MEF}_{25-75}$ ), or contain, as e. g. the Luftibus-Study, a selection bias, since only subjects were investigated, who paid for a lung function test because of their personal request (Kuster [6] $\left.\mathrm{FEV}_{1}, \mathrm{FVC}, \mathrm{FEV}_{1} \% \mathrm{FVC}, \mathrm{PEF}, \mathrm{MEF}_{75,50,25}\right)$. A complete set of parameters is available only from ECCS recommendations $[1,2]$.

The most simple temporary solution is a linear extrapolation of the ECCS reference equations, but an extrapolation is not generally recommended. However, all manufactures have implemented the extrapolation of the data in their systems and lung function laboratories largely use them. This procedure however does not base on a scientific background and raises the question, if one can rely on diagnosis of lung function based on extrapolations.

The problems of the lower limit values and the restricted age range were not solved in a series of publications of the European Task Force on standardisation of lung function testing, recently published in a series of comprehensive recommendations for lung function testing and interpretation [19-21].

We checked on a small, but carefully chosen group of healthy never smoking males aged 18 to 90 years, if the ECCS reference recommendations are still representative in daily routine measurements, and if a linear extrapolation of the ECCS reference values can be performed. A "Bochum" set of reference formulas for lung function parameters in healthy non-smoking males were calculated by multiple linear regression analysis for discussion.

\section{MATERIAL AND Methods}

Lung function tests were performed by pneumotachography, recording static lung volumes and performing forced respiratory manoeuvres on 262 asymptomatic non smoking Caucasian males, aged 20 to 90 years and a height range between 159 and $203 \mathrm{~cm}$. BMI ranged from 20.5 to $35.3 \mathrm{~kg} / \mathrm{m}^{2}$. Subjects were without diseases of the lung, heart or other organs. The subjects were recruited among healthy non-smoking hospital staff members, volunteers, and subjects introducing themselves for a health check to enter a life insurance giving informed consent. The anthropometrical data are presented in Table 1.

\section{Lung Function Measurements}

Lung function measurements [22-24] of static and dynamic lung volumes and maximal expiratory flows and volumes, using MasterLab, or PneumoScreen systems (CareFusion, Höchberg) were performed according to the recommendations and the widely used reference formulas of the ECCS [2]. At first subjects exhaled under normal breathing conditions down to the residual volume (RV), followed by inspiratory vital capacity (IVC) and expiratory vital capacity manoeuvre (EVC). Measurements were repeated until three reproducible recordings were obtained. After recording static lung volumes, at least three reproducible flow volume manoeuvres were performed, starting from residual volume (RV) with a forced inspiration. Only measurements were accepted with times for expiration (TE) exceeding four seconds and without cough disturbed expirations. According to the manufactures guidelines, calibrations were performed daily. Along with inspiratory vital capacity (IVC), forced vital capacity (FVC), forced expiratory volume in one second $\left(\mathrm{FEV}_{1}\right)$ were measured and the ratio of $\mathrm{FEV}_{1}$ and IVC (FEV ${ }_{1} \%$ IVC) was calculated. From the flow-volume loop peak expiratory flow (PEF) and the maximal expiratory flows at $75 \%, 50 \%$ and $25 \%$ of vital capacity $\left(\mathrm{MEF}_{75}, \mathrm{MEF}_{50}, \mathrm{MEF}_{25}\right)$ were analysed.

\section{DATA ANALYSIS}

From the results multiple linear regression lines were calculated for age (20 - 90 years) and body height (159 $-203 \mathrm{~cm})$. The reference formulas for spirometric parameters recorded in the present Bochum study were compared to the reference values of the ECCS, SAPALDIA, and LuftiBus studies.

The results are presented as mean values and standard deviations ( $\mathrm{x} \pm \mathrm{sx})$, along with the median. Zsores related to ECCS reference formulas were obtained by division of the difference between the measured value and the reference value by RSD. Using Fisher's paired t-test, differences of mean values were proofed to be significantly different from reference values of ECCS, SAPALDIA- or LuftiBus- values [25]. P-values $<0.05$ were accepted as significantly different.

Table 1. Anthropometrical Data of $\mathrm{n}=262$ healthy males aged from 20 to 90 years.

\begin{tabular}{|c|c|c|c|c|c|c|c|c|c|c|c|c|}
\hline & \multicolumn{4}{|c|}{ Elder $(n=58)$} & \multicolumn{4}{|c|}{ Middle aged $(n=55)$} & \multicolumn{4}{|c|}{ Young $(n=149)$} \\
\hline & $\begin{array}{c}\text { Age } \\
\text { (years) }\end{array}$ & $\begin{array}{l}\text { Height } \\
(\mathrm{cm})\end{array}$ & $\begin{array}{l}\text { Weight } \\
\text { (kg) }\end{array}$ & BMI & $\begin{array}{l}\text { Age } \\
\text { (years) }\end{array}$ & $\begin{array}{l}\text { Height } \\
(\mathrm{cm})\end{array}$ & $\begin{array}{l}\text { Weight } \\
(\mathrm{kg})\end{array}$ & BMI & $\begin{array}{c}\text { Age } \\
\text { (years) }\end{array}$ & $\begin{array}{l}\text { Height } \\
(\mathrm{cm})\end{array}$ & $\begin{array}{l}\text { Weight } \\
(\mathrm{kg})\end{array}$ & BMI \\
\hline MW & 74.0 & 173 & 77.4 & 25.8 & 57.1 & 177 & 83.8 & 26.8 & 25.4 & 181 & 77.7 & 23.6 \\
\hline STD & \pm 6.4 & \pm 7.4 & \pm 10.3 & \pm 2.4 & \pm 6.4 & \pm 6.5 & \pm 9.4 & \pm 2.7 & \pm 4.9 & \pm 6.5 & \pm 11.1 & \pm 3.0 \\
\hline MAX & 90 & 187 & 100 & 31.6 & 65 & 197 & 106 & 32.1 & 40 & 203 & 123 & 35.3 \\
\hline MIN & 66 & 159 & 60 & 21.7 & 41 & 166 & 68 & 20.5 & 20 & 164 & 55 & 17.0 \\
\hline MED & 72 & 173 & 75 & 25.8 & 60 & 175 & 83 & 26.9 & 25 & 180 & 75 & 23.3 \\
\hline
\end{tabular}




\section{RESULTS}

\section{Anthropometrical Data}

The body height of the males, recruited in the cross sectional study correlated significantly to age, height $=$ $-0.173 *$ age $+185 \mathrm{~cm}(\mathrm{r}=0.49, \alpha<0.01)$. Mean height of a 25 years young subject was $181 \mathrm{~cm}$ and $173 \mathrm{~cm}$ for an 80 years old male.

BMI significantly increased with age, BMI = $0.056^{*}$ age $+22.5(\mathrm{r}=0.37, \alpha<0.01)$. For the younger group, BMI was $23.6 \pm 3.0$ and $25.8 \pm 2.4(\mathrm{p}<0.005)$ for the elderly group. BMI showed a tendency to decrease with height. BMI $=-0.0723 *$ height $+37.9,(\mathrm{r}=$ $0.37, \alpha<0.05)$. There was a slight tendency to lower BMI indices with increasing height, BMI $=$ $0.084 *$ height $+40.2(\mathrm{r}=0.20, \alpha<0.05)$.

\section{Correlation of}

\section{Lung Function Parameters to Age}

For healthy subjects, the relationship to age of all respiratory parameters investigated (VC, FVC, FEV $\left.\mathrm{FEV}_{1} \% \mathrm{FVC}, \mathrm{PEF}, \mathrm{MEF}_{75,50,25}\right)$ can be described with linear regressions $\left(y=-m^{*}\right.$ age $\left.+n\right)$ for comparison with the ECCS reference equations with extended age range until 90 years of age $(\alpha<0.01)$.

Forced vital capacity, FVC, is represented by FVC = $-0.042 *$ age $+6.78 ; \mathrm{r}^{2}=0.62$. Mean FVC for younger subjects was found to be $105 \pm 10.7 \%$ of the EGKS reference values, $106 \pm 13.1 \%$ in middle aged group and $97.5 \pm 11.8 \%$ in the older subjects (Fig. 1).

Lung function parameters calculated as $\%$ predicted also significantly correlate to age $(\alpha<0.01)$. FVC $\%$ pred is represented by $\mathrm{FVC}_{\text {pred }}=-0.111 *$ age $+108 ; \mathrm{r}=$ 0.040 (Fig. 3).

\section{Correlation of}

Lung Function Parameters to Body Height

Lung function parameters, in absolute values and in $\%$ predicted are in accordance with ECCS reference values of body height, indicating a representative match with ECCS reference values. The correspondence of FVC and body height can be described as FVC $=0.090 *$ height $-11.9 ; \mathrm{r}=0.82, \alpha<0.01$, covering the age range from 160 to $202 \mathrm{~cm}$ (Fig. 2).

Lung function parameters given in \%predicted don't show a correlation to body height, these dependencies of lung function values are correctly incorporated in the formulas. FVC\%pred is represented by $\mathrm{FVC}_{\text {pred }}=0.163 *$ height $+79.8 ; \mathrm{r}=0.03$.

\section{Lung Function Parameters Compared to ECCS Reference VAlues}

The frequently used predicted values of lung function in the group of younger males were up to $10 \%$ higher compared to the ECCS reference values. In males older than 65 years results were similar to ECCS predict-
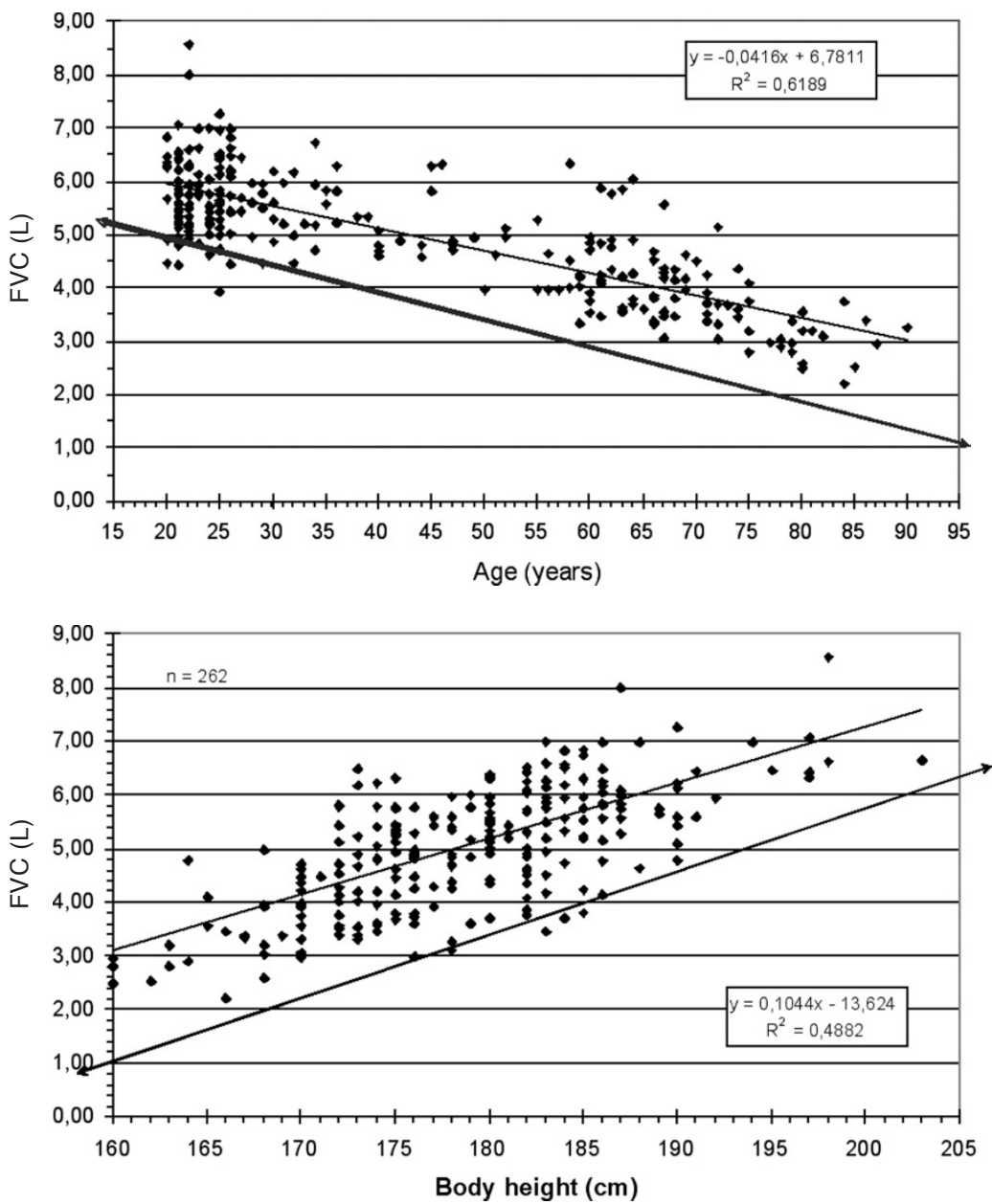

Fig. 1. Regression of FVC on age for healthy non-smoking male adults between 20 and 90 years.
Fig. 2. Regression of FVC on body height for healthy non-smoking male adults with body heights ranging from 160 to $203 \mathrm{~cm}$. 

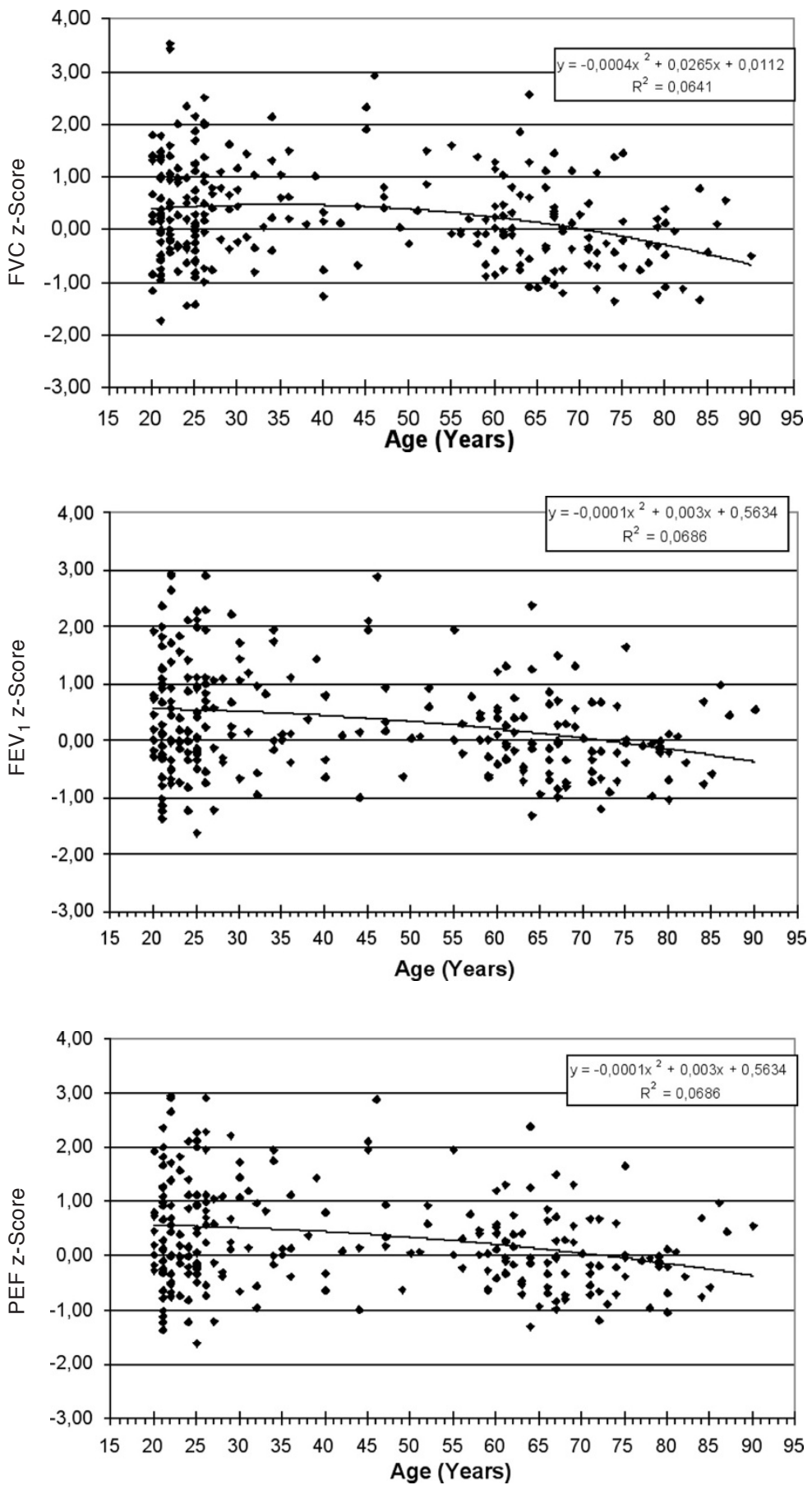

Fig. 3. Regression of z-scores of FVC on age for healthy non-smoking male adults.
Fig. 4. Regression of z-scores of $\mathrm{FEV}_{1}$ on body height for healthy non-smoking male adults. ed values or up to $5 \%$ smaller. The data confirm the steeper gradual reduction of lung function parameters with age compared to ECCS formulas.

\section{Z-SCORes of Lung FunCtion Parameters ON ECCS REFERENCE VALUES}

As observed for respiratory parameters, z-scores for younger males were all positive.

Z-scores for middle aged men were slightly smaller compared to younger males, but were positive with the exemption of $\mathrm{MEF}_{50}(-0.24)$. Values for elderly males were negative with the exemption of $\mathrm{FEV}_{1} \% \mathrm{IVC}$ (0.25). The regression lines, with the exemption of $\mathrm{FEV}_{1} \% \mathrm{IVC}$, had negative slopes, and reached the sig- nificance level $(p<0.05$ or $p<0.01)$ for the correlation of $\mathrm{z}$-score values and age.

\section{Bochum Reference Values for Lung Function Parameters of Males}

Forced expiratory volumes $\mathrm{FVC}$ and $\mathrm{FEV}_{1}$, as well as the maximal expiratory flows PEF and $\mathrm{MEF}_{75,50,25}$ and IVC as a static lung volume of the healthy males regress linearly to both, age and height $(\alpha<0.01)$.

Extending the range of the ECCS-reference functions until 90 years of age (Table 2), the current values, calculated in $\%$ of the predicted values of ECCS also correlate to age but not to height (as above), indicating a steeper slope of the dependency of the listed 


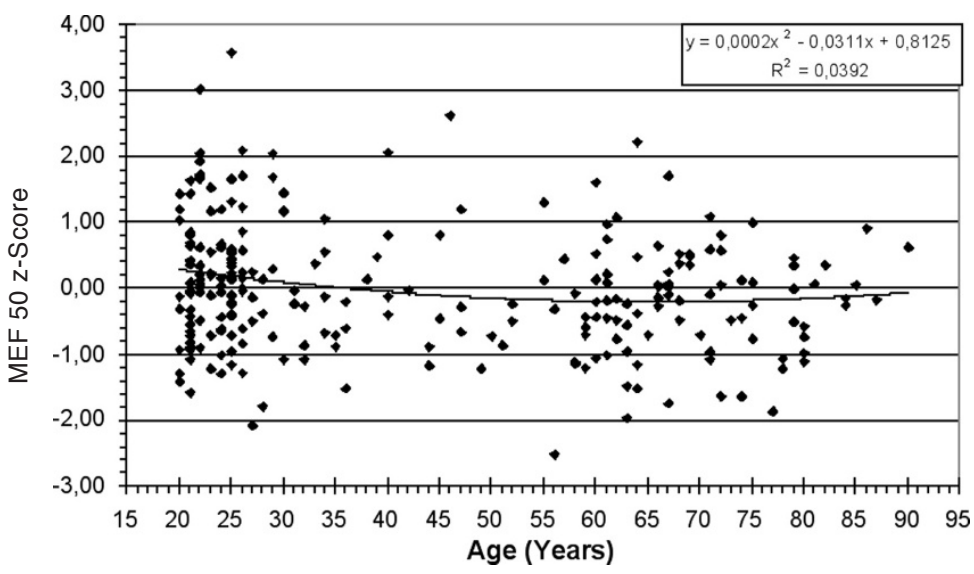

Fig. 6. Regression of z-scores of $\mathrm{MEF}_{50}$ on body height for healthy non-smoking male adults.

Table 2. Values of Lung function parameters in \%pred of ECCS references in elderly, middle aged and younger males.

\begin{tabular}{|c|c|c|c|}
\hline Parameter & $\begin{array}{l}\text { Younger } \\
(\mathrm{n}=149)\end{array}$ & $\begin{array}{l}\text { Middle aged } \\
\quad(\mathrm{n}=55)\end{array}$ & $\begin{array}{c}\text { Elder } \\
(\mathrm{n}=58)\end{array}$ \\
\hline IVC (\%pred) & $100.1 \pm 10.2$ n.s. & $102.3 \pm 12.5$ n.s. & $94.6 \pm 11.0 * * *$ \\
\hline FVC (\%pred) & $104.7 \pm 10.7 * *$ & $105.3 \pm 12.7 * *$ & $96.5 \pm 11.8 *$ \\
\hline $\mathbf{F E V}_{\mathbf{1}}(\%$ pred $)$ & $106.1 \pm 11.2 * * *$ & $104.8 \pm 12.3 * *$ & $97.8 \pm 11.7$ n.s. \\
\hline $\mathrm{FEV}_{1} \% \mathrm{IVC}$ & $100.8 \pm 6.48$ n.s. & $101.2 \pm 7.0$ n.s. & $102.5 \pm 8.5 *$ \\
\hline PEF (\%pred) & $106.2 \pm 16.4 * * *$ & $106.1 \pm 20.4$ n.s. & $96.9 \pm 14.2$ n.s. \\
\hline $\mathbf{M E F}_{50}(\%$ pred $)$ & $104.4 \pm 23.3 *$ & $94.8 \pm 27.4$ n.s. & $94.8 \pm 24.8$ n.s. \\
\hline
\end{tabular}

n.s. non significant, $\quad * \mathrm{p}<0.05, \quad * * \mathrm{p}<0.01, \quad * * * \mathrm{p}<0.001$

Table 3. Z-scores of Lung function parameters on ECCS references.

\begin{tabular}{|c|c|c|c|c|}
\hline Parameter & Young & Middle aged & Elder & z-score regressions \\
\hline IVC-z-score & $\mathbf{0 . 0 1} \pm 0.65$ & $0.16 \pm 0.66$ & $\mathbf{- 0 . 2 1 \pm 0 . 4 8}$ & $\begin{array}{c}Y=-0.0002 x^{2}+0.018 x-0.29 \\
r^{2}=0.017^{*}\end{array}$ \\
\hline FVC-z-score & $\mathbf{0 . 4 2} \pm 0.97$ & $\mathbf{0 . 3 8} \pm 0.89$ & $-\mathbf{0 . 1 6} \pm 0.73$ & $\begin{array}{c}y=-0.001 x^{2}+0.027 x+0.011 \\
r^{2}=0.064^{* *}\end{array}$ \\
\hline $\mathrm{FEV}_{1}$-z-score & $\mathbf{0 . 5 4} \pm 0.99$ & $\mathbf{0 . 3 1} \pm 0.83$ & $\mathbf{- 0 . 0 7} \pm 0.65$ & $\begin{array}{c}\mathrm{Y}=-0.0001 \mathrm{x}^{2}+0,003 \mathrm{x}+0.563 \\
\mathrm{r}^{2}=0.069^{* *}\end{array}$ \\
\hline $\mathrm{FEV}_{1} \%$ IVC-z-score & $\mathbf{0 . 1 0} \pm 0.76$ & $\mathbf{0 . 0 7} \pm 0.79$ & $\mathbf{0 . 2 5} \pm 0.85$ & $\begin{array}{c}\mathrm{Y}=0.0002 \mathrm{x}^{2}-0.01 \mathrm{x}+0.333 \\
\mathrm{r}^{2}=0.010 \text { n.s. }\end{array}$ \\
\hline PEF-z-score & $0.52 \pm 1.37$ & $0.22 \pm 1.40$ & $-0.19 \pm 1.04$ & $\begin{array}{c}\mathrm{Y}=-0.0001 \mathrm{x}^{2}+0.003 \mathrm{x}+0.563 \\
\mathrm{r}^{2}=0.069 * *\end{array}$ \\
\hline $\mathrm{MEF}_{50}$-z-score & $0.19 \pm 1.01$ & $\mathbf{- 0 . 2 4} \pm 0.96$ & $-0.13 \pm 0.73$ & $\begin{array}{c}Y=-0.0002 x^{2}-0.031 x+0.813 \\
r^{2}=0.0392 *\end{array}$ \\
\hline
\end{tabular}

n.s. non significant, $\quad * \mathrm{p}<0.05, \quad * * \mathrm{p}<0.01, \quad * * * \mathrm{p}<0.001$

lung function parameters on age in the subjects investigated.

The residual standard deviation (RSD) of the subjects investigated were slightly, but not significantly smaller compared to the ECCS values of RSD, resulting in slightly higher values for the $5^{\text {th }}$ percentiles.

The Bochum lung function values for healthy males having a steeper slope of the age reduction of 35 $\mathrm{mL} /$ year of the compared to $29 \mathrm{~mL} /$ year in the ECCS formula. At the age of 25 years $\mathrm{FEV}_{1}$ of a male of $180 \mathrm{~cm}$ height, the Bochum values are $300 \mathrm{~mL}$ higher compared to ECCS values. Near the age of 70 years the regression lines cross each other. Since the $5^{\text {th }}$ per- centiles have nearly identical $(0.81 \mathrm{~L}$ and $0.84 \mathrm{~L}$ respectively) the lower limit values only differ in the younger ages.

In a 25 year old male of $180 \mathrm{~cm}$ height, the $5^{\text {th }}$ percentile is $17.8 \%$ smaller compared to the predicted value. At 85 years the difference is $30 \%$ of the predicted value, or nearly twice as much as for a young adult. The coefficients of variation of the measured values in $\%$ predicted of the different lung function parameters were minimally smaller in the groups of young and middle aged males compared to the older group. For $\mathrm{FEV}_{1}$ e.g. the coefficient was 11.9 in the older group, 11.7 in the middle aged and 10.6 in the younger group. 
Table 4. Bochum reference formulas for ventilatory lung function in healthy non-smoking males aged 20 to 90 years ( $\mathrm{n}=262$ ).

\begin{tabular}{|c|c|c|c|c|}
\hline Parameter & Reference formula & $\mathbf{R}^{2}$ & RSD & $1,64 * \mathbf{R S D}$ \\
\hline IVC & $\mathrm{Y}=0.0631 * \mathrm{H}-0.0312 * \mathrm{~A}-4.960$ & 0.73 & 0.58 & 0.96 \\
\hline FVC & $\mathrm{Y}=0.0615^{*} \mathrm{H}-0.0308^{*} \mathrm{~A}-4.673$ & 0.74 & 0.58 & 0.96 \\
\hline $\mathrm{FEV}_{1}$ & $\mathrm{Y}=0.0431 * \mathrm{H}-0.0346 * \mathrm{~A}-2.114$ & 0.78 & 0.49 & 0.81 \\
\hline $\mathrm{FEV}_{1} \% \mathrm{FVC}$ & $\mathrm{Y}=-0.1141 * \mathrm{H}-0.2001 * \mathrm{~A}+110$ & 0.32 & 5.72 & 9.38 \\
\hline PEF & $\mathrm{Y}=0.0742 * \mathrm{H}-0.0538 * \mathrm{~A}+1.3032$ & 0.47 & 1.60 & 2.63 \\
\hline $\mathrm{MEF}_{75}$ & $\mathrm{Y}=0.0579 * \mathrm{H}-0.0227 * \mathrm{~A}-1.3032$ & 0.16 & 1.73 & 2.85 \\
\hline $\mathrm{MEF}_{50}$ & $\mathrm{Y}=0.0211 * \mathrm{H}-0.0449 * \mathrm{~A}+3.270$ & 0.41 & 1.26 & 2.07 \\
\hline $\mathrm{MEF}_{25}$ & $\mathrm{Y}=0.0205^{*} \mathrm{H}-0.0400^{*} \mathrm{~A}-0.800$ & 0.31 & 0.68 & 1.12 \\
\hline
\end{tabular}

$\mathrm{H}=$ body height $(\mathrm{cm}), \mathrm{A}=$ age (years)

\section{Discussion}

The commonly used reference formulas of the ECCS $[1,2]$ for ventilatory lung function were compiled by the ECCS experts from different investigations and subsets of individuals in the seventies, aged less than 70 years. Meanwhile anthropometrical parameters significantly altered, our population is getting older, and technology is largely improved. Classifications of lung function in the elderly base on an extrapolation of the limited age range investigated by ECCS and other studies. In addition, the stringent definition of the lower limit value by subtracting $1.64 *$ RSD with constant RSD wrongs older and smaller subjects compared to younger and taller patients. The definition of the lower limit value ( $5^{\text {th }}$ percentile) is not only important for the discrimination of healthy to diseased, but is also the basis for expert opinions and the amount of compensation for occupational lung diseases.

\section{Age Deterioration of Lung Function Values}

Bochum lung function values for young adults up to healthy 90 years old elderly can be described by linear regression functions on age and body height. Compared to the ECCS reference formulas, the slopes of the functions were steeper since values for younger subjects were higher than predicted and those of the elderly were slightly lower. Z-scores for the younger age group were all positive (range 0.01 to 0.54 ), whereas in older age group $z$-scores were slightly negative (range -0.07 to -0.21 ) with the exemption to $\mathrm{FEV}_{1} \% \mathrm{FVC}(+0.25)$. So, according to the present results on normal lung function an extrapolation of the reference equations beyond common range of age can be justified, since lung function values of elderly were only slightly smaller than ECCS predictions.

\section{Current Reference Values of LuftiBus and SAL-} PAPLDIA

Alternatively to ECCS references, equations obtained from the SALPADIA-Study, and the LuftiBus-Study are higher, but they don't cover all the necessary parameters and/or the age range needed for a comprehensive classification of lung function. ECCS predicted values for $\mathrm{FEV}_{1}$ in comparison to the LuftiBus-Study differ by about $200 \mathrm{~mL}$ in the middle aged males. For younger and older subjects differences are even smaller. The reference values of the SAPALDIA-Study are about $200 \mathrm{~mL}$ higher for young and middle aged males and about $300 \mathrm{~mL}$ for more than 65 years old subjects. Lower limit values are largely similar for young subjects by ECCS and LuftiBus, values for middle aged subjects are about $200 \mathrm{~mL}$ higher in the LuftiBus study. Despite the decrease of more than $1.5 \mathrm{~L}$ from 25 to 80 years of age, the difference between the predicted value and the $5^{\text {th }}$ percentile is nearly constant over the whole range of age. In the original version of the SAPALDIAStudy the lower limit value approximate the predicted values with increasing age [4]. Due to a simplified mathematical model, with respect to the small number of older subjects, the authors newly computed the lower limit values [27]. Now the reference values and lower limit values are almost parallel in the SAPALDIAStudy as we know from ECCS formulas. In the Bochum study, based on data of only 262 healthy subjects, coefficients of variation of the values in \%predicted did not remarkable differ in the younger and older group as one might expect with respect to the differences in FVC of about $2.0 \mathrm{~L}$ between a 25 years and an 85 years old male of $180 \mathrm{~cm}$ body height.

\section{Caucasian Lung Function Multi Centre Study}

The demand for a complete set of reference values, replacing the ECCS recommendations due the altered structures of our population can be realized only with a great financial, material and personal engagement in a multi centre European research project. At least a number of 20.000 subjects have to be recruited from local registration offices, smokers and diseased subjects excluded and only subjects being qualified are allowed to be selected. Selection in higher age groups will be difficult, as we were faced in our study. In a comprehensive reference value project not only static and dynamic lung volumes and maximal flows should be studied, but also parameters of body plethysmography, diffusion capacities and blood gases should be studied with identical devices.

Recently, the European Respiratory Society established a task force for generation of new reference values of lung function with the aim of compiling current data from early childhood to senescence. Stanoje- 
vic and Co-workers have published something like reference values spanning from childhood to senescence $[14,26]$. A set of recommendations for all ages would be highly convenient for the users, solving the problems of overlaps from adolescence to adults. But for statistical reasons this procedure is highly problematic. In childhood the independent variables for lung function parameters are mainly height and weight, but for young adults these are height, age and sex. So there is a discontinuity in the underlying mathematical models.

\section{SUMMARY AND CONCLUSION}

Regress of static and dynamic lung function parameter of healthy non smoking males investigated in the Bochum study exceeds the limits of ECCS reference values. In the investigated range of 20 to 90 years and of 159 to $204 \mathrm{~cm}$ height, multiple linear regressions were computed. Static and dynamic parameters of younger adults were significantly higher and values of elderly adults were slightly lower compared to ECCS values. Using ECCS references as an interim solution, a linear extrapolation beyond the age limit is acceptable. Considering the increasing age and height of our population and the changes in working conditions a multi centre study for contemporary reference values should be performed in order to solve the problems concerning valid reference values.

Conflicts of interest: No conflicts of interest were reported in relation to this article

\section{REFERENCES}

1. Quanjer PH. Standardized lung function testing. Report Working Party Standardization of Lung Function Tests. European Community for Coal and Steel. Bull Eur Physiopathol Respir 1983; 19(Suppl. 5):1-95.

2. Quanjer P, Tammeling GJ, Cotes JE, Pederson OF, Peslin R, Yernault JC. Lung volumes and forced ventilatory flows. Report of the working party standardization of lung functions tests. European Community for Steel and Coal. Eur Respir J. 6[Suppl. 16]. 1993.

3. Hankinson JL, Odencrantz JR, Fedan KB. Spirometric reference values from a sample of the genral U.S. population. Am J Respir Crit Care Med. 159, 179-187. 1999.

4. Brändli O, Schindler N, Künzli R, Keller A, Perruchoud AP, SAPALDIA team. Lung function in healthy never smoking adults: reference values and lower limits of normal of a Swiss population. Thorax 1996; 51:277-282.

5. Roca J, Sanchis J, Agusti-Vidal A, et al. Spirometric reference values for a mediterranean population. Bull Eur Physiopathol Respir 1986; 22:217-224. Ref ID: 30

6. Kuster SP, Kuster D, Schindler C, Rochat MK, Braun J, Held L, Brändli $O$. Reference equations for lung function screening of healthy never-smoking adults aged 18-80 years. Eur Respir J 31, 860-868. 2008.

7. American Thoracic Society. Lung function testing: selection of reference values and interpretative strategies. Official statement of the American Thoracic Society. Am Rev Respir Dis 1991; 144:1202-1218.

8. American Thoracic Society. Standardization of spirometry: 1994 Update. Official Statement of the American Thoracic Society. Am Rev Respir Dis 1995; 152:1107-1136.

9. Crapo RO, Morris AH, Gardner RM. Reference spirometric values using techniques and equipment that meet ATS recomendations. Am Rev Respir Dis 1981; 123:659-664.

10. Knudson RJ, Slatin RC, Lebowitz MD, Burrows B. The maximal expiratory flow-volume curve: normal standards, variability, effects of age. Amer Rev Respir Dis 1976; 113: 587-599.

11. Knudson RJ, Lebowitz MD, Holdberg CJ, Burrows B. Changes in maximal expiratory flow-volume curve with growth and aging. Am Rev Respir Dis 1983; 127:725-734.

12. Enright PL, Kronmal RA, Higgins M, et al. Spirometry reference values for women and men 65 to 85 years of age. Am Rev Respir Dis 1993; 147:125-133.

13. Enright PL, Beck KC, Sherrill DL. Repeatability of spirometry in 18,000 adult patients. Am J Respir Crit Care Med. 169, 235-238. 2004.

14. Stanojevic S, Wade A, Stocks J, Hankinson JL, Coates AL, Pan H, Rosenthal M, Corey M, Lebecque P, Cole TJ. Reference Ranges for Spirometry across all ages. a new approach. Am J Respir Crit Care Med. 177, 253-260. 2008.

15. Fletcher C, Peto R. The natural history of chronic airflow obstruction. B M J 1, 1645-1648. 1977.

16. Wise RA. The value of forced expiratory volume in 1 second decline in the assessment of chronic obstructive pulmonary disease progression. Am J Med 119[Suppl, 10], 411. 2006

17. Molfino NA. Genetic predisposition to accelerated decline of lung function in COPD. Int J Chron Obstruct Pulmon Dis. 2[2], 117-119. 2007.

18. Hnizdo E, Sircar K, Yan T, Harber T, Fleming J, Glindmeyer HW. Limits of longitudinal decline for the interpretation of annual changes in $\mathrm{FEV}_{1}$ in individuals. Occup Environ.Med. 64[10], 701-707. 2007

19. Miller MR, Hankinson JL, Brusasco V, Burgos F, Casaburi R. Standardisation of Spirometry. Eur Respir J 2005; 26:319-338. Ref ID: 388

20. Miller MR, Crapo RO, Hankinson JL, et al. General Considerations of Lung Function Testing. Eur.Respir.J. 26, 153-161. 2005. ATS/ERS Task Force: Standardisation of lung function testing.

21. Pellegrino R, Viegi G, Brusasco V, Crapo RO, Burgos F, et al. Interpretative Strategies for Lung Function Testing. Eur.Respir.J. 26, 948-968. 2005.

22. Marek W, Marek E, Mückenhoff K, Smith HJ, KotschyLang N, Kohlhäufl M. Lungenfunktion im Alter: Brauchen wir neue Referenzwerte? Pneumologie 63, 235-243. 2009.

23. Marek W, Marek E, Mückenhoff K, Smith HJ, Degens P, Kotschy-Lang N, Kohlhäufl M. Time for new reference values for ventilatory lung function. Eur J Med Res 14[Suppl IV], 140-146. 2009.

24. Marek W, Marek EM, Mückenhoff K, Smith HJ, Degens P, Kalhoff H, Kotschy-Lang N, Kohlhäufl M. Lung function in young adults - which references should be taken? Al Ameen J Med Sci in Press. 2010.

25. Sachs L. Angewandte Statistik, Planung und Auswertung, Methoden und Modelle. Berlin, Heidelberg, New York: Springer Verlag, 1992.

26. Stanojevic S, Wade A, Hankinson JL, Coates AL, Stocks J, Cole TJ. Continuous reference ranges for spirometry from childhood to adulthood. Am J Respir Crit Care Med. 176, A606. 2007.

27. Brändli $O$, Leuenberger $P$, Schindler N, Baur X, Degens P, Künzli R, Keller R, Perruchoud AP. Reestimated reference equations for the $5^{\text {th }}$ percentiles of lung function variables in the adults population of Switzerland. (SAPALDIAStudy). Thorax 55, 173-174. 2000.

Received: July 7, 2010 / Accepted: August 2, 2010

Address for correspondence:

PD Dr. rer. nat. Wolfgang Marek

Institute for Occupational Physiology

Augusta-Kranken-Anstalt

Bergstr. 23

44791 Bochum

Tel.: $\quad+492345172474$

E-mail: Wolfgang.Marek@ruhr-uni-bochum.de 